\title{
HUBUNGAN OBESITAS DENGAN PROFIL TEKANAN DARAH PADA ANAK USIA 10-12 TAHUN DI KOTA MANADO
}

\author{
${ }^{1}$ Angelya Lumoindong \\ ${ }^{2}$ Adrian Umboh \\ ${ }^{2}$ Nurhayati Masloman
}

\author{
${ }^{1}$ Kandidat Skripsi Fakultas Kedokteran Universitas Sam Ratulangi Manado \\ ${ }^{2}$ Bagian Ilmu Kesehatan Anak Fakultas Kedokteran Universitas Sam Ratulangi Manado \\ Email: angelyagerald@yahoo.com
}

\begin{abstract}
Obesity is now a global problem. The prevalence is increasing not only in developed countries but also in developing countries. Currently, obesity in children is still a complex issue. The cause is multifactorial, making it hard for the implementation. The increasing of overweight and obesity in children around the world participate to boost the prevalence of hypertension in children. Observing the heredity aspect of hypertension, emerging understanding that hypertension in adults are from children. Therefore, efforts to reduce the prevalence of overweight and obesity will decrease the prevalence of hypertension in children indirectly. Objective: To determine the relationship of obesity with blood pressure in children aged 10-12 years. Methodology: This study was observational analytic cross sectional design. Results: There were 111 children as the subjects of study that meets the inclusion criteria which have been measured. Consisted of 57 girls and 54 boys. Of 111 obese children are 31 children with normal blood pressure, 55 children with high-normal blood pressure and 25 children with high blood pressure, there is a significant relationship with the Chi-Square Test $(p=0.007)$. Conclusion: There is a relationship between obesity and blood pressure appearance in children aged 10-12 years.
\end{abstract}

Keywords: blood Pressure, hypertension, obesity.

\begin{abstract}
Abstrak: Obesitas saat ini sudah menjadi masalah global. Prevalensinya meningkat tidak saja dinegara maju tapi juga di negara-negara berkembang. Obesitas pada anak sampai saat ini masih merupakan masalah yang kompleks. Penyebabnya multifaktorial sehingga menyulitkan penatalaksanaannya. Peningkatan kegemukan dan obesitas pada anak di seluruh dunia ikut mendongkrak prevalensi hipertensi pada anak. Melihat unsur keturunan dari hipertensi, muncul pemahaman bahwa hipertensi pada orang dewasa berasal dari anak-anak. Oleh karena itu upaya menurunkan prevalensi kegemukan dan obesitas akan menurunkan prevalensi hipertensi pada anak secara tidak langsung. Tujuan: Untuk mengetahui hubungan obesitas dengan tekanan darah pada anak usia 10-12 tahun. Metode: Penelitian ini merupakan penelitian observasional analitik dengan rancangan potong lintang. Hasil: Terdapat 111 anak subjek penelitian yang memenuhi kriteria Inklusi yang telah diukur. Terdiri dari 57 anak perempuan dan 54 anak laki-laki. Dari 111 anak obes tersebut 31 anak dengan tekanan darah normal, 55 anak dengan tekanan darah normal tinggi dan 25 anak bertekanan darah tinggi, terdapat hubungan bermakna dengan Uji Chi-Square $(p=0,007)$. Simpulan: Terdapat hubungan antara obesitas dan profil tekanan darah pada anak usia 10 - 12 tahun.
\end{abstract}

Kata Kunci: Hipertensi, Obesitas, Tekanan Darah 
Obesitas merupakan keadaan patologis sebagai akibat dari konsumsi makanan yang jauh melebihi kebutuhannya sehingga terdapat penimbunan lemak yang berlebihan dari apa yang diperlukan untuk fungsi tubuh. ${ }^{1}$ Obesitas saat ini sudah menjadi masalah global. Prevalensinya meningkat tidak saja dinegara maju tapi juga di negara-negara berkembang. Obesitas pada anak sampai saat ini masih merupakan masalah yang kompleks. Penyebabnya multifaktorial sehingga menyulitkan penatalaksanaannya. Obesitas pada anak beresiko tinggi menjadi obesitas pada masa dewasa dan berpotensi mengalami pelbagai penyebab sakit dan kematian dibidang kardiovaskuler dan diabetes militus. $^{2}$

Obesitas dapat menjadi jelas pada setiap umur, tetapi obesitas tampak paling sering pada satu tahun pertama, pada usia 5-6 tahun, dan selama remaja. ${ }^{3}$ Penelitian yang di lakukan Damayanti dkk di sekolah dasar di sepuluh kota besar Indonesia periode 2002-2005 dengan metode acak. Hasilnya menunjukkan prevalensi obesitas pada anak-anak usia sekolah dasar secara berurutan dari yang tertinggi ialah Jakarta (25\%), Semarang (24.3\%), Medan (17.75\%), Denpasar (11.7\%), Surabaya (11.4\%), Padang (7.1\%), Manado (5.3\%), Yogyakarta (4\%) dan Solo (2.1\%). Rata-rata prevalensi obesitas di sepuluh kota besar tersebut mencapai $12.2 \%{ }^{4}$

Tekanan darah merupakan kekuatan yang diperlukan agar darah dapat mengalir dalam pembuluh darah dan beredar mencapai semua jaringan tubuh manusia. Darah yang mengalir ke seluruh tubuh berfungsi sebagai media pengangkut oksigen serta zat-zat lain yang diperlukan bagi kehidupan sel-sel tubuh. ${ }^{5}$ Kalau darah tidak mengalir tubuh akan kekurangan darah dan mengakibatkan kerusakan malah kematian. ${ }^{6}$ Dalam setiap detak jantung tekanan darah bervariasi dalam tekanan darah maksimum (sitolik) dan minimun (diastolik). ${ }^{7}$

Tekanan darah normal pada anak adalah tekanan darah (TDS) dan tekanan darah diastolik (TDD) di bawah persentil 90 berdasarkan jenis kelamin, usia dan tinggi badan. ${ }^{8}$ Menurut U.S Departement of
Health and Human Service dalam The Fourth Report, hipertemsi adalah tekenan darah sistolik dan diastolik yang lebih dari persentil 95 menurut jenis kelamin, usia, dan tinggi badan. ${ }^{9}$ Hipertensi anak dibagi menjadi hipertensi primer dan hipertensi sekunder. Hipertensi primer adalah hipertensi yang tidak jelas penyebabnya, meskipun demikian beberapa faktor dapat menimbulkan seperti faktor keturunan dan berat badan. Hipertensi sekunder merupakan hipertensi yang paling sering ditemukan pada anak dan kebanyakan kasus penyebabnya berhubungan dengan penyakit perenkim dan pembuluh darah ginjal. ${ }^{10.11}$

Melihat unsur keturunan dari hipertensi, muncul pemahaman bahwa hipertensi pada orang dewasa berasal dari anakanak. $^{9}$ Gejala hipertensi pada anak antara lain: pusing, muntah-muntah, gangguan penglihatan, kejang atau koma. ${ }^{12}$

Pada tahun 2000 diperkirakan hampir satu miliar orang atau $26 \%$ populasi dewasa terkena hipertensi diseluruh dunia. ${ }^{13}$ Buch dkk dalam penelitian mereka pada anak-anak umur 6-18 tahun, pada total 1.249 anak, 727 anak laki-laki dan 511 perempuan, ditemukan sebanyak 49 anak lali-laki dengan hipertensi, sedangkan pada anak perempuan sebanyak 32 dengan hipertensi. $^{14}$

Peningkatan kegemukan dan obesitas pada anak di seluruh dunia ikut mendongkrak prevalensi hipertensi pada anak, terutama hipertensi primer. Obesitas diketahui merupakan salah satu faktor yang meningkatkan resiko hipertensi primer pada anak. Oleh karena itu upaya menurunkan prevalensi kegemukan dan obesitas akan menurunkan prevalensi hipertensi pada anak secara tidak langsung. Hipertensi pada anak merupakan fenomena yang mencemaskan karena dapat menimbulkan kerusakan pada pelbagai organ tubuh seperti ginjal, jantung, saraf mata, serta kelainan fungsi otak dan sebagainya. Upaya pencegahan hipertensi dan kegemukan pada anak mesti segera di lakukan. ${ }^{4}$ Prevalensi obesitas (persentil >95) pada anak rentang usia 5-15 tahun sebesar $8,3 \% .^{15}$ 
Hubungan antara obesitas dan hipertensi pada anak telah dilaporkan pada berbagai penelitian berdasarkan etnis dan ras dimana tekanan darah lebih tinggi pada anak obesitas dibandingkan anak dengan berat badan normal. Obesitas memegang peranan penting pada hipertensi esensial. ${ }^{16}$ Anak dengan obesitas memiliki kecendurungan tiga kali lipat untuk menderita hipertensi dibanding dengan anak yang tidak obesitas. ${ }^{17}$

Berdasarkan data keadaan di atas, maka peneliti tertarik untuk mengetahui tentang hubungan obesitas dengan tekanan darah pada anak di SD Katolik 02 St. Theresia Manado, SD Advent 04 Ranotana dan SD Advent 1 Tikala.

\section{METODE PENELITIAN}

Penelitian ini menggunakan penelitian observasional analitik dengan rancangan potong lintang.

Populasi penelitian adalah siswa SD Katolik 02 St. Theresia Manado, SD Advent 04 Ranotana dan SD Advent 01 Tikala.
Sampel penelitian yang diambil dari siswa kelas V-VI dengan kriteria yaitu Anak laki-laki dan perempuan yang berusia 10-12 tahun yang sehat dan tergolong obese. Anak laki-laki dan perempuan yang tercatat dalam register sekolah. Telah mendapat persetujuan untuk mengikuti penelitian.

Penelitian dilaksanakan pada bulan November-Desember 2012.

\section{HASIL PENELITIAN}

Penelitian ini dilakukan pada anak sekolah dasar yang berada di Manado, dan yang menjadi sumber penelitiannya adalah SD Advent 04, SD Katolik 02 St. Theresia dan SD Advent 01. Hasil penelitian berdasarkan data yang tersedia dapat diolah dengan menggunakan analisis mencakup sekolah dan jenis kelamin, umur, tekanan darah dan analisis hubungan Obesitas dengan tekanan darah. Jumlah keseluruhan anak yang berumur 10-12 tahun di sekolahsekolah dasar tersebut adalah 316 siswa.

Tabel 1. Profil jumlah keseluruhan anak berusia 10-12 tahun di Sekolah dasar.

\begin{tabular}{cccc}
\hline & & \multicolumn{2}{c}{ JUMLAH SISWA } \\
No & KLASIFIKASI & $\mathrm{N}$ & $\%$ \\
\hline 1 & SEKOLAH & & \\
& SD ADVENT RANOTANA & 98 & 31 \\
& SD KATOLIK 02 Sta. Theresia & 78 & 24.6 \\
& SD ADVENT TIKALA & 140 & 44.3 \\
& & & \\
& JENIS KELAMIN & & 50.6 \\
& LAKI-LAKI & 160 & 49.3 \\
& PEREMPUAN & 156 & \\
& & & 39.8 \\
& UMUR TAHUN & 126 & 37.9 \\
& 11 TAHUN & 120 & 22.1 \\
\hline
\end{tabular}


Tabel 2. Jumlah sampel anak obes yang diperiksa.

\begin{tabular}{lllll}
\hline Nama Sekolah & Laki-laki & Perempuan & Jumlah & Persentase \\
\hline SD Advent 04 Ranotana & 19 & 23 & 42 & 37.8 \\
SD Katolik 02 St. theresia & 14 & 8 & 22 & 19.8 \\
SD Advent 01 Tikala & 21 & 26 & 47 & 42.3 \\
\hline Total & 54 & 57 & 111 & 100 \\
\hline
\end{tabular}

Tabel 3. Distribusi menurut umur.

\begin{tabular}{llll}
\hline No. & Umur Responden & $\mathrm{N}$ & $\%$ \\
\hline 1. & 10 tahun & 49 & 44,1 \\
2. & 11 tahun & 34 & 30,6 \\
3. & 12 tahun & 28 & 25,2 \\
\hline & Total & 111 & 100 \\
\hline
\end{tabular}

Tabel 4. Distribusi tekanan darah.

\begin{tabular}{llll}
\hline No. & Tekanan Darah & $\mathrm{N}$ & $\%$ \\
\hline 1. & Normal & 31 & 27,9 \\
2. & Tinggi & 25 & 22,5 \\
3. & Normal Tinggi & 55 & 49,5 \\
\hline & Total & 111 & 100 \\
\hline
\end{tabular}

Tabel 5. Distribusi tekanan darah berdasarkan kelamin.

\begin{tabular}{llcll}
\hline \multirow{2}{*}{ Terkanan darah } & \multicolumn{4}{c}{ Jenis Kelamin } \\
\cline { 2 - 6 } & \multicolumn{2}{c}{ Laki-laki } & P & $\%$ \\
\cline { 2 - 5 } & $\mathrm{N}$ & 37 & 11 & 19.2 \\
Normal & 20 & 42.5 & 32 & 56.1 \\
Normal tinggi & 23 & 20.3 & 14 & 24.5 \\
Tinggi & 11 & & 57 & \\
\hline \multicolumn{1}{c}{ Jumlah } & 54 & &
\end{tabular}

Tabel 6. Hubungan obesitas dengan tekanan darah.

\begin{tabular}{|c|c|c|c|c|c|c|c|}
\hline & & & Tekanan Darah & & & Total & \\
\hline & Normal & & Tinggi & $\begin{array}{l}\text { Normal } \\
\text { Tinggi }\end{array}$ & & Jlh & \\
\hline Obes & 41 & 29,7 & 22,5 & 55 & 49,5 & 111100 & 0,007 \\
\hline
\end{tabular}

Berdasarkan tabel 2, dapat dilihat jumlah sampel terdiri dari 111 responden, yang berjenis kelamin perempuan dengan jumlah 57 responden (51,4\%) dan jenis kelamin laki-laki dengan jumlah 54 responden (48,6\%). Berdasarkan sekolah diperolah hasil: SD Advent 04 dengan jumlah 42 responden (37.8\%), SD Katolik 02 St. Theresia dengan jumlah 22 responden (19.8\%) dan SD 01 Tikala dengan jumlah 47 responden (42.3\%).

Berdasarkan tabel 3, dapat dilihat karakteristik umur, dan dari 111 responden penelitian sebagian besar berada pada golongan umur 10 tahun dengan jumlah 49 responden $(44,1 \%)$, umur 11 tahun dengan jumlah 34 responden (30,6\%), umur 12 tahun dengan jumlah 28 responden (25,2\%).

Berdasarkan tabel 4, dapat dilihat karakteristik tekanan darah, dimana dari 111 responden penelitian sebagian besar mempunyai tekanan darah normal tinggi dengan jumlah 55 responden (49,5\%), normal dengan jumlah 31 responden (27,9\%), dan tinggi dengan jumlah 22 responden (22,5\%).

Dari data tabel 5, distribusi tekanan darah berdasarkan jenis kelamin didapatkan jenis kelamin laki-laki tekanan darah 
normal dengan jumlah 20 responden (37.0\%), tekanan darah normal tinggi dengan jumlah 23 responden (42.5\%) dan tekanan darah tinggi 11 responden (20.3\%). Untuk jenis kelamin perempuan didapatkan tekanan darah normal dengan jumlah 11 responden $(19.2 \%)$, tekanan darah normal tinggi 32 responden (56.1\%), dan tekanan darah tinggi 14 responden (24.5\%).

Berdasarkan analisis data pada tabel 6, dapat dilihat bahwa seluruh responden obes dengan tekanan darah normal berjumlah 31 responden (29,7\%), responden obes dengan tekanan darah tinggi berjumlah 25 responden $(22,5 \%)$ dan responden obes dengan tekanan darah normal tinggi berjumlah 55 responden (49,5\%). Analisis data yang digunakan untuk mengetahui hubungan Obesitas dengan tekanan darah adalah uji Chi-Square dengan menggunakan tingkat kepercayaan 95\% dan tingkat kesalahan $5 \%(\alpha=0,05)$. Hasil analisis data diperoleh nilai $p=0,007<0,05$, sehingga hipotesis nol (Ho) ditolak dan hipotesis alternatif (Ha) diterima, dengan demikian dapat disimpulkan bahwa ada hubungan yang bermakna antara Obesitas dengan tekanan darah.

Berdasarkan hasil uji univariat pada variabel umur semua responden adalah tergolong pada usia sekolah yaitu 10 tahun sampai 12 tahun. Beberapa faktor penyebab obesitas pada anak antara lain asupan makanan berlebih yang berasal dari jenis makanan olahan serba instan, minuman soft drink, makanan jajanan seperti makanan cepat saji (burger, pizza, hot dog) dan makanan siap saji lainnya yang tersedia di gerai makanan. ${ }^{14}$

Obesitas terjadi akibat ketidakseimbangan jumlah kalori yang masuk lewat makanan dan minuman lebih besar dari pada jumlah kalori yang dikeluarkan untuk tumbuh kembang, metabolisme maupun beraktifitas, ketidakseimbangan itu dipengaruhi oleh berbagai faktor antara lain faktor perilaku. Perilaku yang sering dijumpai saat ini dikalangan anak-anak yaitu makan makanan berkalori tinggi namun bernutrisi rendah seperti yang banyak dijual di restoran cepat saji dan kurangnya aktifitas fisik anak lebih banyak menghabiskan waktu dengan menonton TV atau main game. Faktor lingkungan juga berpengaruh terhadap obesitas pada anak yaitu di lingkungan rumah dan lingkungan luar rumah seperti sekolah, tempat pengasuhan atau komunitas bermain. Lingkungan ini sangat berperan dalam mempengaruhi perilaku anak terutama pola makan dan aktifitas fisik.

Berdasarkan analisis data pada tabel 5 dapat dilihat bahwa seluruh responden obes dengan tekanan darah normal berjumlah 31 responden (29,7\%), responden obes dengan tekanan darah tinggi berjumlah 25 responden $(22,5 \%)$ dan responden obes dengan tekanan darah normal tinggi berjumlah 55 responden (49,5\%).Hal ini menunjukkan bahwa dengan kejadian obesitas pada anak kecenderungan tekanan darah menjadi tinggi akan semakin nyata. Hasil penelitian menggunakan uji chi square diperoleh nilai $\mathrm{p}=0,007<0,05$, dimana terdapat hubungan antara obesitas dengan tekanan darah. Penelitian Romdhonah menyatakan bahwa ada hubungan IMT dengan tekanan darah pada anak usia sekolah. Anak-anak yang mengalami obesitas dapat berisiko lebih besar mengidap penyakit jantung, diabetes dan gangguan akibat kelebihan berat badan lainnya dari yang terpikirkan. Fakta ini diketahui berdasarkan studi baru tentang dampak obesitas selama masa kanak-kanak dan perkembangan kesehatan di masa dewa-sa. Dibanding anak-anak dan remaja yang berbobot ideal, anak dengan obesitas lebih berisiko menderita gangguan kesehatan yang memicu penyakit jantung dan diabetes seperti, tekanan darah tinggi, kadar kolesterol tinggi, dan gula darah tinggi. ${ }^{18}$

Hasil pada penelitian ini sama dengan hasil penelitian sebelumnya pada anak di SMP 4 Tondano. ${ }^{19}$ Hubungan antara obesitas dan hipertensi telah lama diketahui namun mekanisme yang pasti bagaimana terjadinya hipertensi akibat obesitas hingga saat ini belum jelas. Sebagian peneliti menitikberatkan patofisiologi tersebut pada tiga hal utama yaitu adanya gangguan sistem autonom, resistensi insulin serta abnormalitas struktur dan fungsi pembuluh 
darah. Patogenesis obesitas sehingga mengakibatkan suatu hipertensi merupakan hal yang kompleks karena penyababnya multifaktor dan saling berhubungan. Leptin, asam lemak babas dan insulin serta obstruktive sleep apnea yang meningkat pada anak obes akan menyebabkan konstriksi dan aktifitas sistem saraf simpatis. Resistensi insulin dan disfungsional endothelial juga menyebabkan vasokonstriksi. Peningkatan aktifitas saraf simpatis ginjal, resistensi insulin dan hiperaktifitas sistem renin angiotensi menjadikan reabsorbsi natrium pada ginjal meninggi. Semua faktor diatas akan mengakibatkan terjadinya hipertensi. ${ }^{20}$ Diet dan faktor daya hidup lainnya memainkan peran penting dalam prefalensi hipertensi, banyak perilaku pencegahan dengan mengurai faktor resiko kardio vaskuler lain antara lain dengan mengontrol berat badan, olahraga, mengatur pola diet, dan menghindari rokok. ${ }^{21}$

\section{SIMPULAN}

Berdasarkan hasil yang dilakukan maka dapat disimpulkan bahwa terdapat hubungan antara obesitas dan profil tekanan darah pada anak. Oleh karena itu perlu dilakukan penyuluhan dan edukasi untuk anak maupun orang tua tentang pola makan yang baik, sehat dan bagaimana mencegah obesitas. Dilakukan deteksi sedini mungkin pada anak yang mempunyai berat badan lebih dan obes. Perlunya menanamkan pendidikan kesehatan pada anak sejak usia dini, melalui peningkatan komunikasi, informasi dan edukasi seperti gerakan anti rokok, gerakan cinta serat (sayur dan buah), berolahraga.

\section{DAFTAR PUSTAKA}

1. Soetjiningsih. Tumbung kembang remaja dan permasalahannya. Jakarta: Sagung Seto; 2004 hal 77-86.

2. Sjarif D. Obesitas pada anak dan permasalahannya. Dalam: Prohino P, Purnamawati S, Sjarif D, Hagar B, Gunandi H, Oswari H, dkk (penyunting). Hot topics in pediatric II. Jakarta:
Fakultas Kedokteran Universitas Indonesia RS. Dr Ciptomangunkusumo, 2002; Hal.219-34.

3. Nelson, Behrman, Kliegman, Arvin. Ilmu Kesehatan Anak Nelson (Vol. 1) (Edisi Kelimabelas) Jakarta: Penerbit Buku Kedokteran ECG, 2000; h.216.

4. Wahyu GG. Obesitas Pada Anak. Bentang Pustaka, 2009; hal.13.

5. Gunawan L. Hipertensi Tekanan Darah Tinggi. Yogyakarta: Kanisius, 2001;h. 7.

6. Lumbantobing SM. Tekanan Darah Tinggi. Jakarta: Balai Penerbit FKUI, 2008;hal.3.

7. Luma GB, Spiotta RT. Jamaica Hospital Madical Center. Hypertens Child Adolesc 2006:73:1558-68. Available from: http://www.aafp.org./ 2006/0501/p1558.html.

8. Partha. Hipertensi Pada Anak. Indian J Ped 2002:6:1077-81.

9. National High Blood presure Education Program Working Group in High Blood presure in children and adolescents. The fourth report on the diagnosis, evaluation, and treatment of high blood pressure in children and adolescents. Pediatrics 2004:114:555-76.

10. Supartha M. Suarta IK, Widaya IBA. Hipertensi pada anak. Maj Kedok Indon. 2009:59:5.

11. Alatas H, Tambunan $T$, Trihono PP, Perdede SO. Nefrologi Anak: Hipertensi Sistemik (Edisi Kedua). Jakarta: Ikatan Dokter Indonesia, 2002; 243-287.

12. Insley J. Vademeaceum pediatri. Edisi ke13. Jakarta: Penerbit buku kedokteran EGC, 2005; Hal.84-5.

13. Kearney PM, Whelton M, Reynolds K, Muntner P, Whelton PK, He J. Global burden of hypertension: analysis of worldwide data, Vol:365, Januari 2005. Diakses dari: www.sld.cu/ galerias/pdf/servicious/hta/global_burd en_of_hypertension.pdf

14. Buch N, Goyal JP, Kumar N, Palmar I, Shah VB, Charan J. Prevelence of hypertension in school going children of Surat City, Wastern India. JCDR 2011 Nov;2(4):228-32.

15. Sartika RAD. Faktor Resiko Obesitas Pada Anak 5-15 Tahun di Indonesia Riskesdas tahun 2007: Makara KesehatanUI 2011:15:1;37-43.

16. Hall J. The kidney, hypertension and obesitas. Hypertension 2003;41:625 
17. Makmur NI. Pengaruh latihan fisik terhadap tekanan darah anak Obesitas di kotamadya. Medan. (thesis). FK. Universiatas Sematra Utara. 2008. Diakses dari: http://repository.usu.ac. id./bitstrean/123456789/20748/pengaru h-latihan-fisik-terhadap-tekanan-darahanak-obes-dikotamadya-medan.

18. Romdhonah. Hubungan antara beberapa indikator obesitas dengan tekadan darah pada anak sekolah. Semarang: Artikel Penelitian. Program Studi Ilmu Gizi Undip, 2008.

19. Terok FR. Hubungan Status Gizi dan tekanan darah pada anak umur 12-14 tahun di SMP 4 Tondano. Manado: Universitas Samratulangi, 2010.

20. Makmur NI. Pengaruh latihan fisik terhadap tekanan darah anas obes di Kotamadya Medan (thesis). FK Universitas Sumatera Utara. 2008. Diakses dari: http://repository.usu.ac.id./bitstream/12 345678/20748/pengaruh-latihan-fisikterhadap-tekanan-darah-anak-obes-dikotamadya-medan.

21. Beilin LJ. Lifestyle and hypertension overview. Clin Exp Hypertens 1999;21; 5-6:\&749-62. 